\title{
Statistical analysis of Lagrangian transport of subtropical waters in the Japan Sea based on AVISO altimetry data
}

\author{
Sergey V. Prants, Maxim V. Budyansky, and Michael Yu. Uleysky \\ Laboratory of Nonlinear Dynamical Systems, Pacific Oceanological Institute of the Russian Academy of Sciences, \\ 43 Baltiyskaya st., 690041 Vladivostok, Russia \\ Correspondence to: Sergey V. Prants (prants@poi.dvo.ru)
}

Received: 2 November 2016 - Discussion started: 9 November 2016

Revised: 20 January 2017 - Accepted: 29 January 2017 - Published: 16 February 2017

\begin{abstract}
Northward near-surface Lagrangian transport of subtropical waters in the Japan Sea frontal zone is simulated and analysed based on altimeter data for the period from 2 January 1993 to 15 June 2015. Computing different Lagrangian indicators for a large number of synthetic tracers launched weekly for 21 years in the southern part of the Sea, we find preferred transport pathways across the Subpolar Front. This cross-frontal transport is statistically shown to be meridionally inhomogeneous with "gates" and "barriers" whose locations are determined by the local advection velocity field. The gates "open" due to suitable dispositions of mesoscale eddies facilitating propagation of subtropical waters to the north. It is documented for the western, central and eastern gates with the help of different kinds of Lagrangian maps and verified by some tracks of available drifters. The transport through the gates occurs by a portion-like manner, i.e. subtropical tracers pass the gates in specific places and during specific time intervals. There are some "forbidden" zones in the frontal area where the northward transport has not been observed during all the observation period. They exist due to long-term peculiarities of the advection velocity field.
\end{abstract}

\section{Introduction}

The Japan Sea (JS) is a mid-latitude marginal sea with dimensions of $1600 \times 900 \mathrm{~km}$, the maximal depth of $3.72 \mathrm{~km}$ and the mean depth of about $1.5 \mathrm{~km}$. It spans regimes from subarctic to subtropical and is characterised by many of the same phenomena found in the deep ocean: fronts, eddies, currents and streamers, deep water formation, convection and subduction. It communicates with the Pacific Ocean at the south and east through the Tsushima/Korean and Tsugaru straits, respectively. In the north it is connected with the Okhotsk Sea through the Soya (La Perouse) and Tatarsky straits. All the four channels are shallow with depths not exceeding $135 \mathrm{~m}$. Bathymetry of the JS and its geographic and oceanographic features are shown in Fig. S1 in the Supplement.

Warm and saline Pacific waters enter the Tsushima Strait and split into three currents. Figure 1 with the AVISO velocity field, averaged for the period from 2 January 1993 to 15 June 2015, reflects the main known features of mesoscale near-surface circulation in the JS (Lee and Niiler, 2005; Danchenkov et al., 2006; Talley et al., 2006; Yoon and Kim, 2009; Kim and Yoon, 2010; Lee and Niiler, 2010; Ito et al., 2014). The Nearshore Branch of the Tsushima Current flows northward along the western coast of the Honshu Island (Japan). Its Offshore Branch with a meander-like path flows into the Yamato Basin. The East Korean Warm Current flows northward along the eastern coast of Korea to meet the North Korean Cold Current which is a prolongation of the Liman Cold Current flowing southward along the Siberian coast down to Vladivostok. One of the major large-scale features in the northern JS is a cyclonic gyre over the Japan Basin and the Tatarsky Strait. Some well-known persistent mesoscale eddy-like features are also indicated in Fig. 1. In the Ulleung Basin there are the warm Ulleung anticyclonic circulation (Chang et al., 2004; Mitchell et al., 2005; Shin, 2009; Lee and Niiler, 2010) with the centre at about $37^{\circ} \mathrm{N}, 130.5^{\circ} \mathrm{E}$ and a cyclonic circulation around $36.7^{\circ} \mathrm{N}, 132^{\circ} \mathrm{E}$ often called the cold Dok Eddy (Lee and Niiler, 2010). The flow over bottom topography around the Oki Spur in the southeastern 
part of the Sea generates the anticyclonic Oki Eddy $\left(37.5^{\circ} \mathrm{N}\right.$, $134.2^{\circ} \mathrm{E}$ ) (Isoda, 1994). In the western part of the Sea meandering of the East Korean Warm Current produces an anticyclonic circulation called as the anticyclonic Wonsan Eddy $\left(39^{\circ} \mathrm{N}, 129^{\circ} \mathrm{E}\right)($ Lee and Niiler, 2005).

The confluence of northward warm subtropical waters with southward cold subarctic ones forms one of the most remarkable features in the JS - the distinct Subpolar Front that extends across the basin near $40^{\circ} \mathrm{N}$ (Park et al., 2004; Talley et al., 2006). It is a boundary of physical and chemical properties such as temperature, salinity, dissolved oxygen and nutrients. Like many other hydrological fronts, the Subpolar Front is a highly productive zone with favourable fishery conditions. It is not a continuous curve crossing the basin with a maximal thermal gradient. It is rather a vast area between 38 and $41^{\circ} \mathrm{N}$ extending across the basin from the Korea coast to the Japanese islands. Understanding transport pathways of subtropical water in the JS is relevant to a number of applications. Physical properties (temperature and salinity), chemical properties, pollutants and biota (phytoplankton, zooplankton, larvae, etc.) are transported and mixed by currents and eddies. Transport of heat to the north is crucial for climatic applications. The ability to simulate transport adequately would be useful to deal with the aftermath of accidents at sea such as discharges of radionuclides, pollutants and oil spills. It is also crucial, for instance, for understanding transport pathways for species invasions.

Since the last decades in the twentieth century, invasions of heat-loving fish (conger eel, tuna, moonfish and triggerfish) and some tropical and subtropical marine organisms (turtles, sharks and others) have been observed in the northern part of the JS, near the coast of Russia (Ivankova and Samuilov, 1979). It is natural to assume that such invasions could be caused by intrusions of subtropical waters in the northern part of the sea across the Subpolar Front. They may be also one of the reasons for a prolongation of the warm period in the fall in Primorye province in Russia since the 1990s (Nikitin et al., 2002). From the oceanographic point of view, this transport of subtropical waters contradicts long-held beliefs on circulation in the JS. It is believed that the Subpolar Front is a transport barrier for propagation of subtropical waters to the north, at least in the western and central parts of the front area (see e.g. Danchenkov et al., 2006). In this paper we use altimetry data to simulate and analyse the northward near-surface transport of subtropical waters across the frontal area from 2 January 1993 to 15 June 2015.

The paper is organised as follows. Section 2 introduces briefly the altimetry data and simulation methods we use. Northward transport of subtropical waters across the frontal area is studied statistically in Sect. 3 for a long period of time. We compute, document and discuss preferred transport pathways and meridional distributions of artificial tracers launched in the southern part of the sea. Supplement data can be found in the online version.

\section{Data and methods}

Geostrophic velocities were obtained from the AVISO database (http://aviso.altimetry.fr) archived daily on a $1 / 4^{\circ} \times$ $1 / 4^{\circ}$ grid from 2 January 1993 to 15 June 2015. Our Lagrangian approach is based on solving equations of motion for a large number of passive synthetic particles (tracers) advected by the AVISO velocity field

$$
\frac{\mathrm{d} \lambda}{\mathrm{d} t}=u(\lambda, \varphi, t), \quad \frac{\mathrm{d} \varphi}{\mathrm{d} t}=v(\lambda, \varphi, t),
$$

where $u$ and $v$ are angular zonal and meridional velocities, $\varphi$ and $\lambda$ are latitude and longitude, respectively. Bicubical spatial interpolation and third-order Lagrangian polynomials in time are used to provide numerical results. Lagrangian trajectories are computed by integrating Eq. (1) with a fourth-order Runge-Kutta scheme with an integration step of 1/1000 day. The merged TOPEX/POSEIDON and ERS-1/2 altimeter data sets have been shown by Choi et al. (2004) to be appropriate to study mesoscale surface circulation in the JS because of their comparatively small temporal and spatial sampling intervals. In particular, they have been shown to correlate well (0.95) with tide gauge data in the western JS (Choi et al., 2004).

We study northward transport of tracers in the central part of the JS basin between 37 and $42^{\circ} \mathrm{N}$. With this aim $10^{5}$ tracers have been launched weekly from 2 January 1993 to 15 June 2013 at the latitude $37^{\circ} \mathrm{N}$ from 129 to $138^{\circ} \mathrm{E}$. Trajectory of each tracer has been computed for 2 years after its launch date. We fixed the location and the moment of time where and when each tracer crossed a given latitude in the central JS between 37 and $43^{\circ} \mathrm{N}$. We take into account the first crossing only, because we are interested not in a net transport but in the northward transport. We stop to compute trajectories of those tracers which get into an AVISO cell with at least two corners situated at the land.

Each water parcel can be attributed to temperature, salinity, density and other properties which characterise this volume as it moves. In addition, each water parcel can be attributed to more specific characteristics which are trajectory functions called "Lagrangian indicators". They are, for example, a distance passed by a fluid particle, its displacement from an original position, its travel time and others. The Lagrangian indicators contain information about the origin, history and fate of the corresponding water masses. Lagrangian maps are plots of Lagrangian indicators versus particle initial positions. A studied area is seeded with a large number of tracers whose trajectories are computed for a given period of time to get the field of a specific Lagrangian indicator whose values are coded by colour and represented as a map in geographic coordinates.

To simulate and analyse transport across the frontal area, we solve successively a few tasks which are numbered in the text in accordance with the following diagrams and Lagrangian maps. 


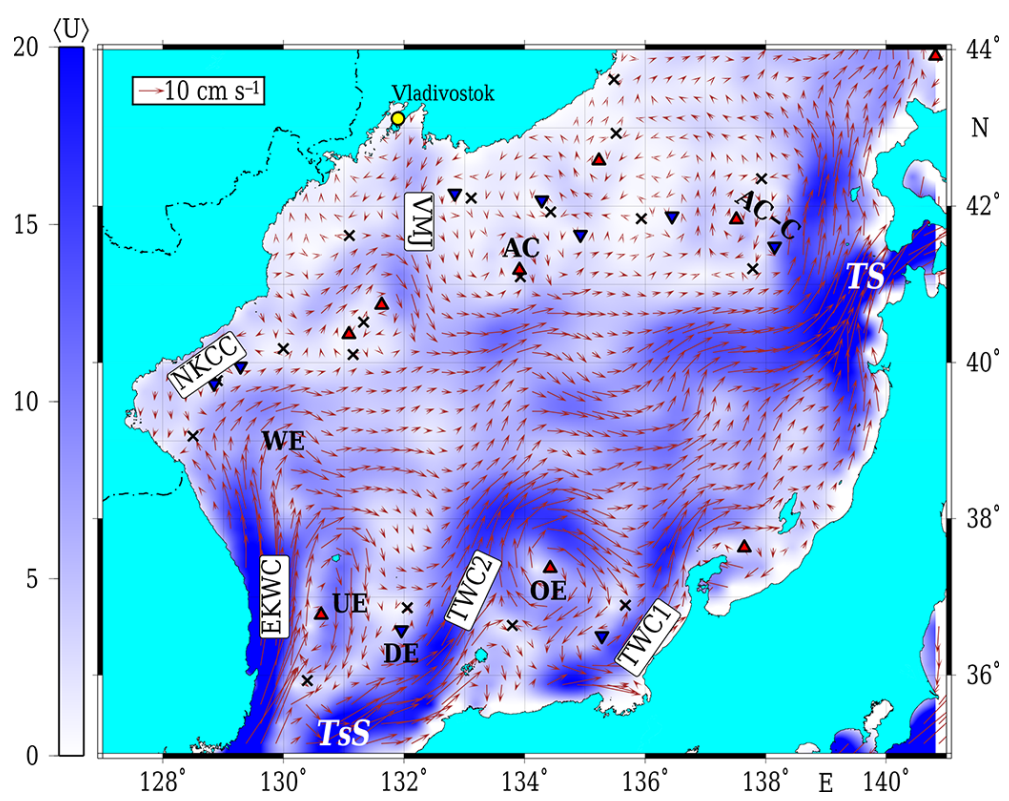

Figure 1. The AVISO velocity field averaged for the period from 2 January 1993 to 15 June 2015. Elliptic and hyperbolic stagnation points with zero mean velocity are indicated by triangles and crosses, respectively. Abbreviations: TsS (Tsushima or Korean Strait), TS (Tsugaru Strait), EKWC (East Korean Warm Current), NKCC (North Korean Cold Current), TWC1 and TWC2 (the first and second branches of the Tsushima Warm Current, UE (Ulleung Eddy), DE (Dok Eddy), OE (Oki Eddy), WE (Wonsan Eddy), AC-C (vortex pair near the eastern gate), AC (anticyclonic eddy over the Japan Basin), VMJ (Vladivostok meridional jet).

1. A meridional distribution of the number of tracers, $N$, crossing fixed latitudes, $\lambda_{\mathrm{f}}$, in the central JS with a space step $0.1^{\circ}$. The corresponding data are represented as a density map which shows by colour the density of tracks of the particles crossed all the latitudes in the central JS from 2 January 1993 to 15 June 2015. Tracking maps show where the subtropical tracers, which crossed eventually the fixed zonal line through fixed meridional "gates", wandered for the whole integration period. They also can be represented as a $N\left(\lambda_{\mathrm{f}}\right)$ distribution which shows how many tracers reached a fixed zonal line at the longitude $\lambda_{\mathrm{f}}$ for the whole period of integration.

2. Fixing initial longitudes $\lambda_{0}$ of launched tracers along the material line $37^{\circ} \mathrm{N}$, we compute those final longitudes $\lambda_{\mathrm{f}}$ at which they cross a fixed zonal line for the whole period of integration. The results are represented as $\lambda_{0}-$ $\lambda_{\mathrm{f}}$ plots.

3. The $T-\lambda_{\mathrm{f}}$ plots show when and at which longitudes the tracers, launched at $37^{\circ} \mathrm{N}$, crossed the latitudes 40 and $42^{\circ} \mathrm{N}$ for the whole period of integration.

4. In order to document and visualise intrusions of subtropical waters into subarctic ones, we compute backward-in-time Lagrangian maps (Prants, 2015). A subbasin in the sea is seeded at a fixed date with a large number of tracers whose trajectories are computed backward in time for a given period of time. We use three kinds of Lagrangian map in this paper. Such maps have been shown to be useful in studying largescale transport and mixing in various basins, from bays (Prants et al., 2013) and seas (Prants et al., 2011a, 2013) to the ocean scale (Prants et al., 2011b; Prants, 2013), in quantifying propagation of radionuclides in the Northern Pacific after the accident at the Fukushima Nuclear Power Plant (Prants et al., 2011b, 2014a; Prants, 2014; Budyansky et al., 2015) and in finding potential fishing grounds (Prants et al., 2014b, c).

In order to track those subtropical waters which were able to cross the Subpolar Front and reach northern latitudes, we colour the tracers that reached the line $37^{\circ} \mathrm{N}$ in the past and compute how much time it took. In order to know where this or that tracer came from for a given period of time, we compute the drift maps with boundaries. The waters that entered a given area through its southern boundary are shown by one colour, and waters that came through the northern boundary are shown by another colour. The drift maps show in greyscale the finite-time displacement of tracers, $D$, that is a distance between final, $\left(\lambda_{\mathrm{f}}, \varphi_{\mathrm{f}}\right)$, and initial, $\left(\lambda_{0}, \varphi_{0}\right)$, positions of advected particles on the Earth sphere with the radius $R_{\mathrm{E}}$ :

$D \equiv R_{\mathrm{E}} \arccos \left[\sin \varphi_{0} \sin \varphi_{\mathrm{f}}\right.$

$\left.+\cos \varphi_{0} \cos \varphi_{\mathrm{f}} \cos \left(\lambda_{\mathrm{f}}-\lambda_{0}\right)\right]$.

"Instantaneous" stagnation elliptic and hyperbolic points are indicated by triangles and crosses, respectively. They 
are points with zero velocity which are computed daily. Up(down)ward orientation of one of the triangle's top means anticyclonic (cyclonic) rotations of water around them. The triangles are coloured as (blue), marking elliptic points for anticyclones (cyclones). The elliptic points, situated mainly in the centres of eddies, are those stagnation points around which the motion is stable and circular. The hyperbolic points, situated mainly between and around eddies, are unstable ones with the directions along which waters converge to such a point and another directions along which they diverge. The stagnation points are moving Eulerian features and may undergo bifurcations in the course of time. In spite of nonstationarity of the velocity field some of them may exist for weeks and much more.

We have used for a comparison and verification tracks of surface drifters that are available at the site http://aoml.noaa. gov/phod/dac.

\section{Results and discussion}

\subsection{Northward transport of subtropical water and advection velocity field}

Figure 2a shows the density of tracks of tracers launched along $37^{\circ} \mathrm{N}$ and across all the latitudes in the central JS for the whole period of integration. The density is shown in greyscale in the logarithmic scale, $\log _{10} N_{\varphi}$. The magenta areas in Fig. 2a along the coastal line indicate that the AVISO grid cells there touch the land, and we did not compute trajectories there. An uneven density of points in Fig. 2a means that the northward transport of subtropical waters is meridionally inhomogeneous with "gates" with increased density of points. The gates are such spatial intervals along a given zonal line across which subtropical tracers prefer to cross.

Any tracer, as a passive particle, is able to cross the fixed latitude in the northward direction if the northward component of the velocity field is nonzero at its location. In Fig. 2b we plot distribution of the northward component of the AVISO velocity field averaged over the whole period of integration as follows:

$\left\langle v_{+}(\lambda, \varphi)\right\rangle=\frac{1}{n} \sum \theta(v(\lambda, \varphi)) v(\lambda, \varphi)$,

where $v_{+}(\lambda, \varphi)$ is a northward (positive) component of the velocity at the point $(\lambda, \varphi), \theta(v)$ the Heaviside function and $n$ the number of days in the period from 2 January 1993 to 15 June 2015. Comparing the Lagrangian representation in Fig. 2a with the Eulerian one in Fig. 2b, it is clear that areas with increased density of points in Fig. 2a correlate well with areas with increased average values of the northward component of the AVISO velocity field in Fig. 2b. Thus, the northward transport of subtropical waters in the central JS is determined mainly by the local advection velocity field, more precisely by local values of its northward component.
The greater is that northward component at a given point and the longer is the period of time when it is positive, the more tracers are able to cross the corresponding latitude.

The density difference in some meridional ranges in Fig. 2a may be very large because of the logarithmic-scale representation. There are even some places in the northern frontal area where the northward transport has not been observed during all the simulation period, from 1993 to 2015. They are marked by magenta rectangles in Fig. 2a. One "forbidden" zone is situated in the deep Japan Basin with the centre at about $41.5^{\circ} \mathrm{N}, 134.2^{\circ} \mathrm{E}$, and another one is situated to the south off Vladivostok from 43 to $41^{\circ} \mathrm{N}$ approximately along the $132^{\circ} \mathrm{E}$ meridian. We stress that they are forbidden only to northward transport of tracers but can be and really are open to transport in other directions.

The "forbidden" zones exist due to long-term peculiarities of the advection velocity field there. The zone to the south off Vladivostok exists due to a quasi-permanent southward jet approximately along the meridian $132^{\circ} \mathrm{E}$ from 43 to $40^{\circ} \mathrm{N}$ (VMJ in Fig. 1). It turns to the east at about $40^{\circ} \mathrm{N}$ and contributes to the eastward transport. In fact, the northward velocity is practically zero in this area (see Fig. 2b) and, therefore, the northward transport is absent. The other "forbidden" zone exists due to two factors: the presence of a quasi-permanent anticyclonic eddy with the centre at about $41.3^{\circ} \mathrm{N}, 134^{\circ} \mathrm{E}$ in the deep Japan Basin (AC in Fig. 1) and the eastward zonal jet blocking northward transport across it. Topographically constrained anticyclonic eddies with the centre at about $41-41.5^{\circ} \mathrm{N}, 134-134.5^{\circ} \mathrm{E}$ have been regularly observed there (Takematsu et al., 1999; Talley et al., 2006; Prants et al., 2015).

\subsection{Transport pathways of subtropical water and its intrusions across the Subpolar Front}

Now let us look more carefully at the meridional distribution of subtropical tracers crossed the Subpolar Front for the whole period of simulation. We choose for reference four zonal lines along the AVISO grid at 42.125, 41.875, 40.125 and $39.875^{\circ} \mathrm{N}$. They are shown in Fig. 3 by solid curves with superimposed meridional distributions of the averaged northward AVISO velocity (arrows). The number of crossings of those latitudes by the available 333 drifters is shown by dashed curves. The correspondence between the peaks in the meridional distributions of the tracers, drifters and the averaged northward AVISO velocity is rather good for all the chosen zonal lines, confirming their direct connection. However, the comparison with drifters should be taken with care because of a comparatively small number of available drifters. Drifters are not ideal passive tracers, and their motion is subjected to submesoscale features which were not caught by altimetry-derived data. Moreover, the drifters have not been launched at the zonal line $37^{\circ} \mathrm{N}$ like artificial tracers in simulation. Their launch sites for more than 20 years have been distributed rather randomly over the basin. 


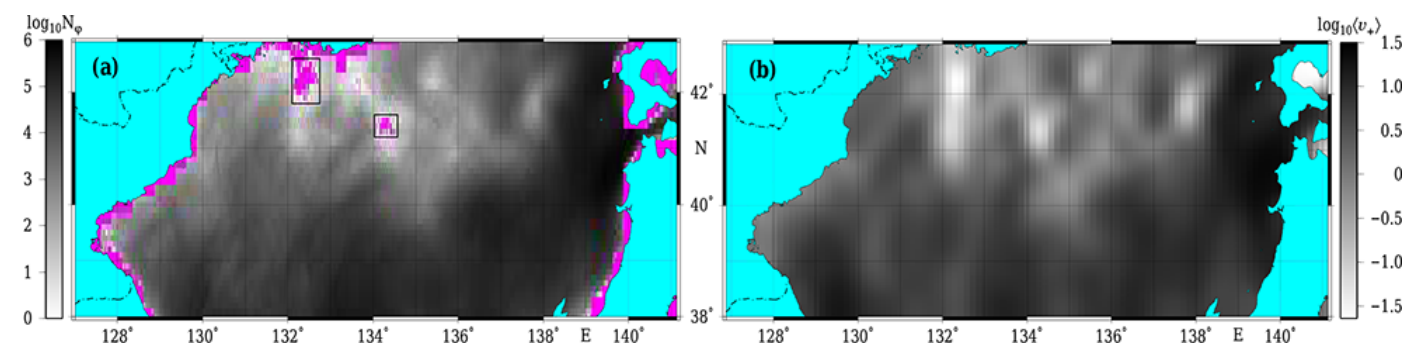

Figure 2. (a) The logarithmic-scale density of tracks of the tracers crossing all the latitudes $\varphi$ in the central JS, $N_{\varphi}$, from 2 January 1993 to 15 June 2015. The rectangular magenta areas are forbidden zones where the northward transport has not been observed during the whole integration period. The magenta areas near the coast mean that the AVISO grid cells there touch the land, and we did not compute trajectories there. The tracers have been launched weekly along the zonal line at $37^{\circ} \mathrm{N}$ from 2 January 1993 to 15 June 2013. (b) Distribution of the averaged northward component of the AVISO velocity field $\left\langle v_{+}(\lambda, \varphi)\right\rangle$ in the logarithmic-scale averaged over the same period.

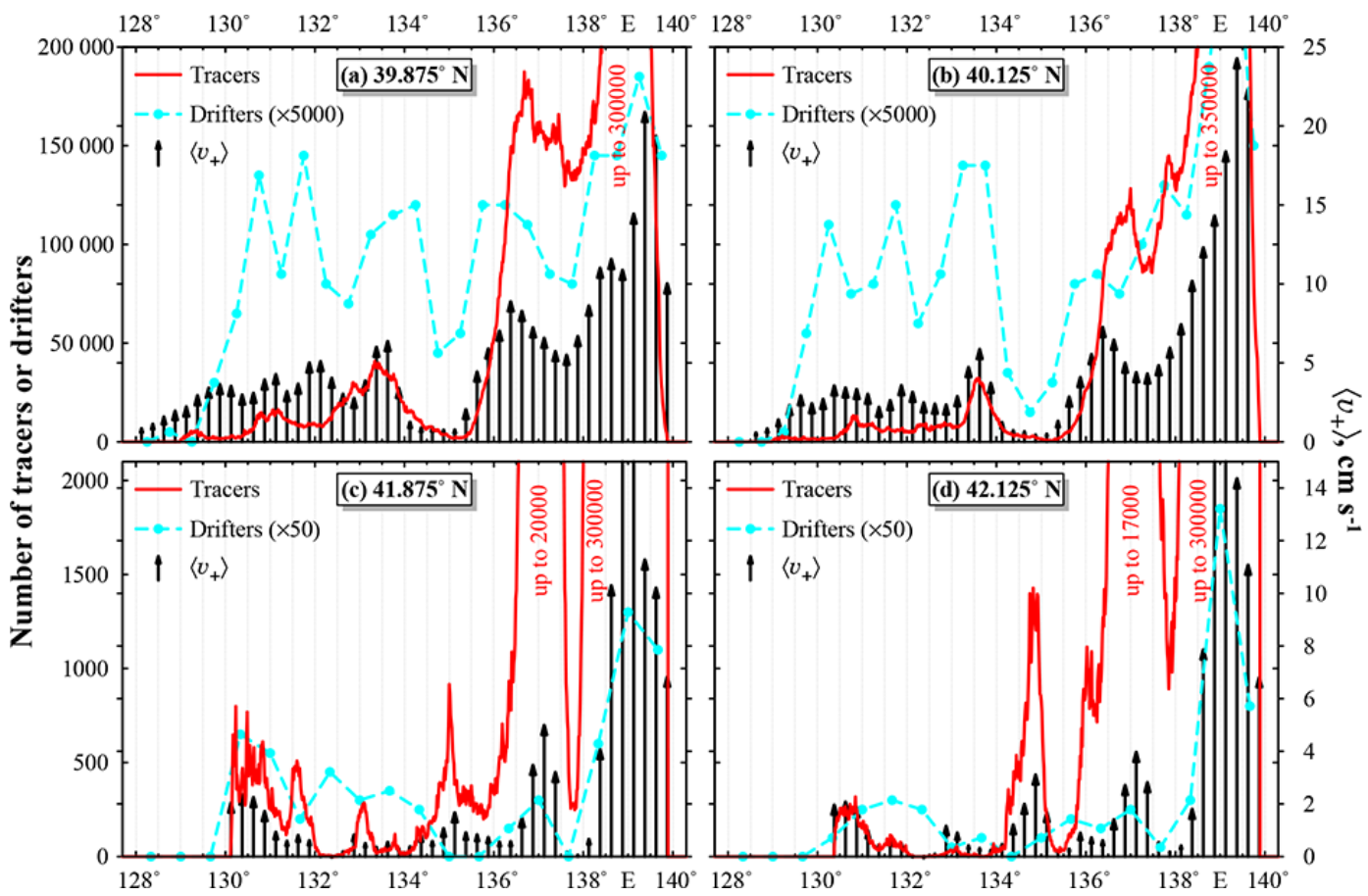

Figure 3. Meridional distributions of the number of tracers which crossed indicated zonal lines (solid curves), of the averaged northward component of the AVISO velocity in $\mathrm{cm} \mathrm{s}^{-1}$ (arrows) and of the number of crossings of those zonal lines by available drifters (dashed curves). The period of observation is from 2 January 1993 to 15 June 2015.

The local maxima and minima of the distribution functions correspond to gates and conditional barriers, respectively. The very eastern, $138-140^{\circ} \mathrm{E}$, and western, $129-131^{\circ} \mathrm{E}$, gates are provided mainly by the near-shore branch of the Tsushima Warm Current and the East Korean Warm Current, respectively. The central gate, $133-137^{\circ} \mathrm{E}$, probably exists due to topographically constrained features over the Yamato Rise there (see Fig. S1 in the Supplement). The transport through that gate will be shown to be enhanced due to a specific disposition of frontal eddies regularly observed there. The intervals between the gates may be called "conditioned barriers" because of a comparatively small number of tracers crossing zonal lines there, and because they used to "open" for comparatively short time intervals.

Figure $4 \mathrm{a}, \mathrm{b}$ shows in accordance with task 2 at which final longitudes $\lambda_{\mathrm{f}}$ the tracers, launched with the initial longitudes $\lambda_{0}$ at the line $37^{\circ} \mathrm{N}$, reached the zonal lines 40 and $42^{\circ} \mathrm{N}$ for the whole period of integration. The meridional distribution of the number of tracers with pronounced peaks which crossed the zonal line $42^{\circ} \mathrm{N}$ for the same period is plotted in Fig. 4c. This zonal line was divided into eight meridional intervals numbered by the roman numerals in Fig. $4 \mathrm{~b}$ and $\mathrm{c}$ with horizontal straight lines running via local minima at the distribution in Fig. 4c. 


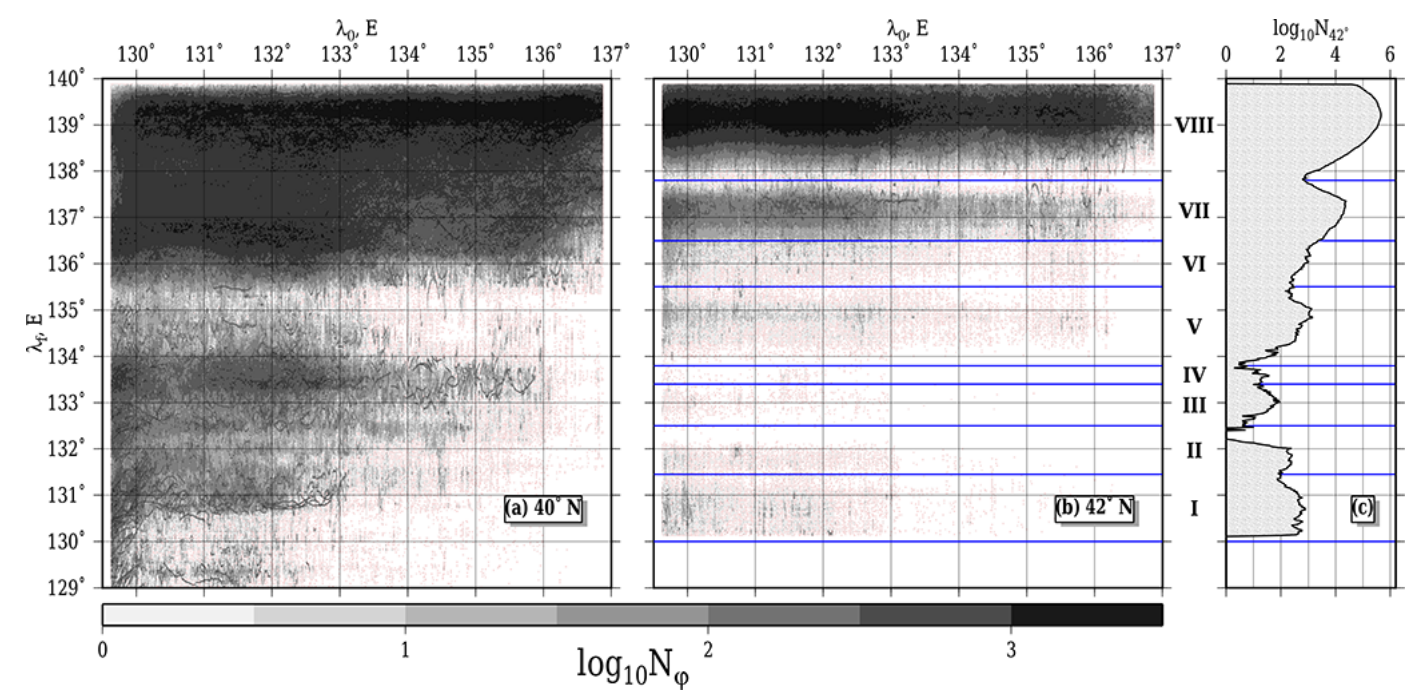

Figure 4. Density plots show in the logarithmic scale how many and at which final longitudes $\lambda_{\mathrm{f}}$ the tracers with initial longitudes $\lambda_{0}$ were able to cross the zonal lines (a) $40^{\circ} \mathrm{N}$ and (b) $42^{\circ} \mathrm{N}$ for the whole simulation period. The tracers were launched weekly at the line $37^{\circ} \mathrm{N}$ from 2 January 1993 to 15 June 2013. (c) Meridional distribution of the number of tracers which crossed the zonal line $42^{\circ} \mathrm{N}$ for the whole simulation period. This line is divided into eight intervals numbered by Roman numerals.

The Tsushima Warm Current contributes mainly to the eastern peak VIII in the distribution in Fig. 4c. Black across all the range of initial longitudes $\lambda_{0}$ in Fig. $4 \mathrm{~b}$ indicates that fluid particles, crossing eventually the line $42^{\circ} \mathrm{N}$ through the gate $138-140^{\circ} \mathrm{E}$, could have any value of the initial longitude $\lambda_{0}$ at the zonal line $37^{\circ} \mathrm{N}$. They could reach that gate in different ways: either to be initially trapped by the near shore branch or to be advected by the offshore branch and then to enter the near-shore branch. Moreover, those particles could be involved initially in the East Korean Warm Current and then be transported to the east along the Subpolar Front to eventually join the Tsushima Warm Current. Thus, the subtropical tracers, crossing the gate VIII, may have rather distinct values of some Lagrangian indicators, e.g. travelling time and distance passed.

There is a narrow barrier, the white strip in Fig. $4 \mathrm{~b}$ between gates VIII and VII, with the centre at the local minimum at $137.8^{\circ} \mathrm{E}$ in Fig. 4c. A comparatively small number of tracers have been able to cross the line $42^{\circ} \mathrm{N}$ there for the whole simulation period. Gate VII between 136 and $137.8^{\circ} \mathrm{E}$ (Fig. 4b, c) provides northward transport of subtropical tracers by means of a quasi-permanent vortex pair located there. The number of subtropical tracers passing through this gate is much smaller than that passing through gate VIII (remember the logarithmic scale in Fig. 4). Only a small number of tracers, launched initially at the very eastern part of the zonal line $37^{\circ} \mathrm{N}$, were able to cross the line $42^{\circ} \mathrm{N}$ through that gate, because most of the eastern tracers passed through the gate VIII to be captured by the near-shore branch of the Tsushima Warm Current. Most of the tracers passing through gate VII came from the western and central parts of the material line at $37^{\circ} \mathrm{N}$. The numbers of subtropical tracers passing through the central and western gates are much smaller as compared with those passing by the eastern ones. We distinguish two central gates V and III, 134-135.5 and 132.5$133.5^{\circ} \mathrm{E}$, respectively, and the western gates I and II (Fig. 4c) in the range $130-132.5^{\circ} \mathrm{E}$. It follows from Fig. $4 \mathrm{~b}$ that the western and central gates collect subtropical tracers mainly from the western part of the initial zonal line, from 129 to $133^{\circ} \mathrm{E}$. In other words, water parcels from its eastern part $\left(133-137^{\circ} \mathrm{E}\right)$ practically do not pass through those gates at the latitude $42^{\circ} \mathrm{N}$. Thus, the western part of the initial material line at $37^{\circ} \mathrm{N}$ contributes to all the peaks in the tracer distribution $42^{\circ} \mathrm{N}$, whereas its eastern part contributes mainly to the Tsushima peak.

To visualise the transport paths by which subtropical tracers reach the northern frontal area we compute so-called tracking maps in Fig. S4 in the Supplement showing where the subtropical tracers, which crossed eventually the zonal line $42^{\circ} \mathrm{N}$, wandered for the whole integration period.

The $T-\lambda_{\mathrm{f}}$ plots in Figs. S2 and S3 in the Supplement show when and at which longitudes the tracers, launched weekly at the zonal line $37^{\circ} \mathrm{N}$ from 2 January 1993 to 15 June 2013, reached the zonal lines 40 and $42^{\circ} \mathrm{N}$, respectively. This was designated in Sect. 2 as task 3. As an example, we show in Fig. 5 a typical $T-\lambda_{\mathrm{f}}$ plot for the tracers crossed eventually the zonal lines 40 and $42^{\circ} \mathrm{N}$ in the period from 1 March 1995 to 1 March 1996. This demonstrates the eastern gates VIII and VII (Fig. 4) through which the subtropical tracers cross the corresponding latitudes. The locations of the central and western gates fluctuate in time, and some gates may be even closed for a while to the northward transport. The patchiness in the plot means that subtropical tracers prefer to cross the zonal lines in specific places (note the peaks in Figs. 3) and 

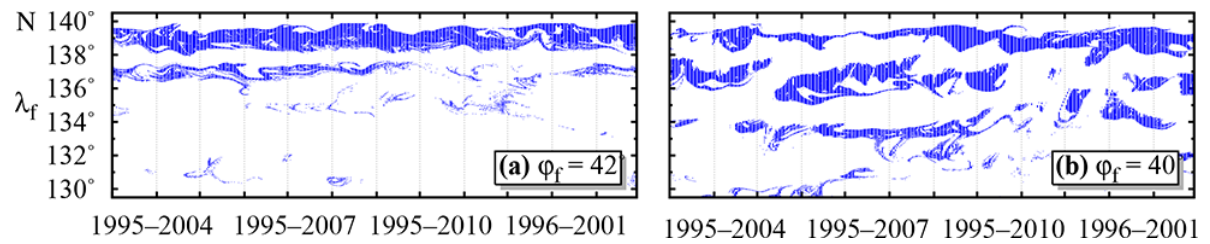

Figure 5. The $T-\lambda_{\mathrm{f}}$ plots show when and at which longitudes the tracers, launched at the zonal line $37^{\circ} \mathrm{N}$, eventually crossed the zonal lines (a) $40^{\circ} \mathrm{N}$ and (b) $42^{\circ} \mathrm{N}$ in the period from 1 March 1995 to 1 March 1996.

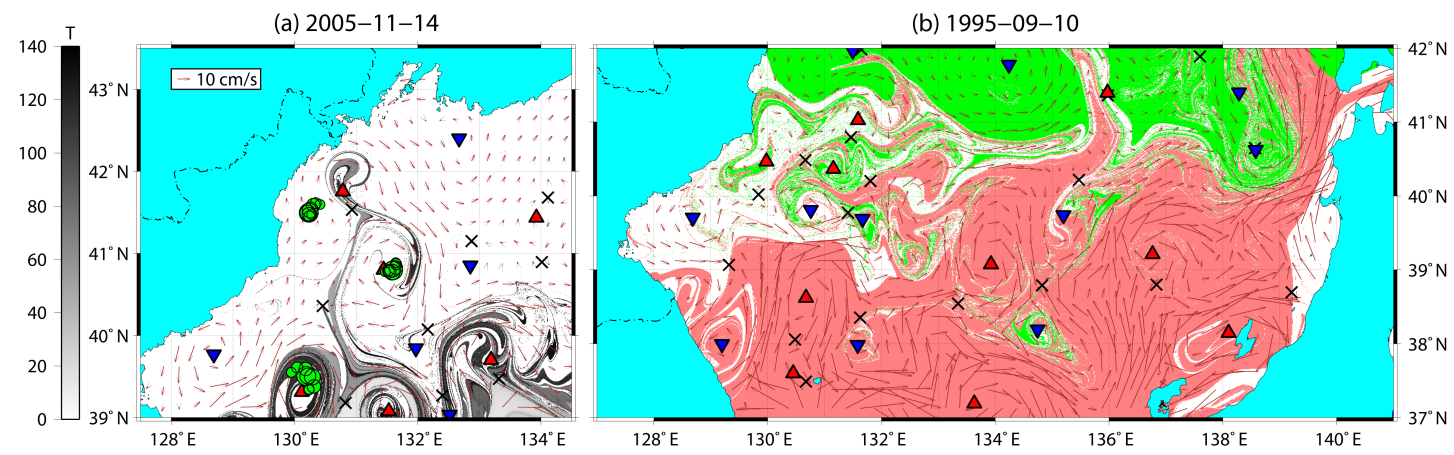

Figure 6. (a) The Lagrangian map documents intrusions of subtropical water to the southern coast of Russia through the western gate. Greyscale shows travelling time $T$ in days that it took for subtropical tracers to reach their locations on the map from latitude $37^{\circ} \mathrm{N}$ to the dates shown. "White" tracers are those which did not come from latitude $37^{\circ} \mathrm{N}$ for the integration period, 140 days. Locations of available drifters are shown by full circles for 1 day before and after the dates indicated. (b) The drift map documents a streamer-like northward transport of subtropical water across the front through a central gate with the help of the cyclone with the centre at $41.5^{\circ} \mathrm{N}, 134.4^{\circ} \mathrm{E}$. Red and green code the waters that entered the studied area for 2 years through its southern and northern boundaries, respectively. White indicates the tracers arriving at the coast.

during specific time intervals. Any patch with a large number of tracers somewhere, for example at the central meridional gate, means that a water mass proportional to the size of this patch passed through the central gate across a given latitude during the period of time proportional to its zonal size. Thus, the northward transport of subtropical water across the Subpolar Front occurs in a proportion-like manner. Specific oceanographic conditions may arise in a given area and at a given time which produce a large-scale intrusion of subtropical water to the north by means of mesoscale eddies present there.

To document intrusion of subtropical water there, we compute the backward-in-time Lagrangian maps (for a recent review of backward-in-time techniques see Prants, 2015). This is a realisation of task 4 in Sect. 2. The basin, shown in Fig. 6a, is seeded with a large number of tracers for each of which we compute the time required for a tracer to reach its location on the map on a fixed date from the latitude $37^{\circ} \mathrm{N}$. This is what is known as a residence-time map (Lipphardt et al., 2006; Uleysky et al., 2007; Hernández-Carrasco et al., 2013). The travelling time $T$ in days is shown in greyscale. The map in Fig. 6a illustrates the mechanism of penetration of subtropical water northward through the western gate. A vortex street with four anticyclones is formed in the fall of 2005 to the north of the Subpolar Front in the western part of the sea. Their centres are marked in Fig. 6a by the triangles at coordinates $39.1^{\circ} \mathrm{N}, 131.5^{\circ} \mathrm{E} ; 39.3^{\circ} \mathrm{N}, 130.1^{\circ} \mathrm{E} ; 40.8^{\circ} \mathrm{N}$, $131.4^{\circ} \mathrm{E}$ and $41.7^{\circ} \mathrm{N}, 130.8^{\circ} \mathrm{E}$. Subtropical "grey" tracers propagate along the unstable manifolds of the three hyperbolic points between and around the eddies to the north (a simple description of the notion of stable and unstable manifolds in fluid flows can be found e.g. in Prants, 2014). The hyperbolic points are marked by crosses in Fig. 6a with the coordinates $39.2^{\circ} \mathrm{N}, 130.8^{\circ} \mathrm{E} ; 40.3^{\circ} \mathrm{N}, 130.5^{\circ} \mathrm{E}$ and $41.6^{\circ} \mathrm{N}$, $130.9^{\circ} \mathrm{E}$. Thus, the vortex street provides an intrusion of subtropical water towards the southern coast of Russia. The evidence of at least two anticyclones in the AVISO velocity field is confirmed by tracks of two available drifters. Their locations are shown in Fig. 6a by full circles for 1 day before and after the date indicated on the map. Drifter no. 56739 has been trapped by the anticyclone with centre at $39.3^{\circ} \mathrm{N}$, $130.1^{\circ} \mathrm{E}$ and drifter no. 56746 by the anticyclone with centre at $40.8^{\circ} \mathrm{N}, 131.4^{\circ} \mathrm{E}$. We have found similar episodes with penetration of subtropical waters far to the north to the coast of Russia through the western gate in different years. Peripheries of mesoscale eddies in the ocean are known to be transport pathways larvae, fish and other marine organisms (see e.g. Cotte et al., 2010; Prants, 2013; Prants et al., 2014c; and references therein). In our case they might be transport for 

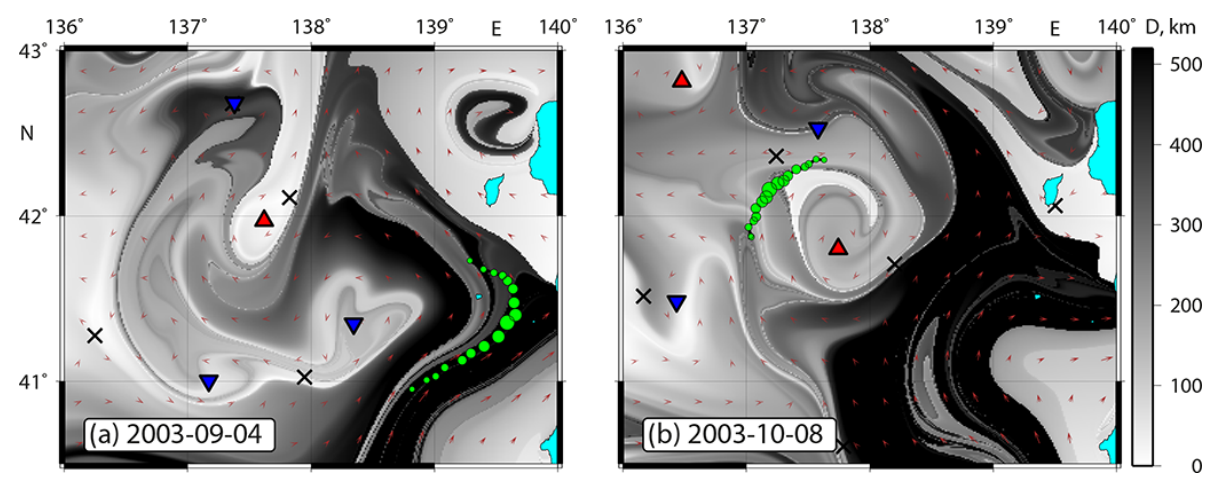

Figure 7. The drift maps in (a) September and (b) October of 2003 with snapshots of the drifter's track superimposed show how the vortex pair facilitates transport of subtropical tracers to the northwest through the eastern gate.

heat-loving organisms to reach the southern coast of Russia (Ivankova and Samuilov, 1979).

An example of the intrusion of subtropical water through the central gate across the Subpolar Front is shown in Fig. $6 \mathrm{~b}$ with another kind of Lagrangian map, the so-called backward-in-time drift maps (Prants et al., 2011a, 2014a) computed as part of task 4 . The red and green colours in the backward-in-time drift maps code the waters that entered the studied area for 2 years through its southern and northern boundaries, respectively. At the beginning of September 1995 a mesoscale cyclonic eddy to the north of the Subpolar Front with centre at about $41.5^{\circ} \mathrm{N}, 134.4^{\circ} \mathrm{E}$ "grabbed" some subtropical water at its southern periphery and pulled it to the north. In the course of time the streamer-like intrusion of subtropical tracers reached latitude $42^{\circ} \mathrm{N}$ moving to the north (Fig. 6b).

The transport of subtropical waters through the eastern gate VII (see Figs. 3 and 4) occurs mainly due to the existence of a quasi-permanent vortex pair labelled AC-C in the mean field in Fig. 1. This provides a propulsion of some subtropical tracers to the northwest whereas most of them, propagating along the eastward frontal jet, join with the Tsushima Warm Current and flow out to the Pacific through the Tsugaru Strait. The maps in the Supplement (Figs. S5 and S6) document a typical situation with a propulsion of subtropical water to the northwest in September-October 2003. The study and analysis of Lagrangian drift maps, computed for the whole observation period, have shown that frontal eddies facilitated the northward transport of subtropical water across the Subpolar Front via the central and eastern gates.

To illustrate how this quasi-permanent vortex pair works we show in Fig. 7 the drift map for tracers distributed over the area and advected for 2 months backward in time starting from the dates indicated. The values of displacements of the tracers, $D$, in $\mathrm{km}$ are shown in greyscale. The black tracers have been displaced for the same time considerably as compared to the white ones. To verify our simulation we show in Fig. 7 positions of drifter no. 35660 by full circles for 2 days before and after the date indicated with their size increasing in time. The entire track of that drifter, launched on 2 May 2003 at the point $34.925^{\circ} \mathrm{N}, 129.3^{\circ} \mathrm{E}$, is shown in Fig. S7 in the Supplement.

At the beginning of September 2003 (Fig. 7a) the vortex pair at the entrance to the gate VII consists of an anticyclone with the centre at about $42^{\circ} \mathrm{N}, 137.7^{\circ} \mathrm{E}$ and a cyclone at $41.25^{\circ} \mathrm{N}, 138.35^{\circ} \mathrm{E}$. The cyclone pulls some subtropical water from the eastward frontal jet round its northern periphery in a streamer-like manner (see the black tongue in Fig. 7a). Then this water is wound by the anticyclone round its southern periphery and propelled northeast. This is confirmed by snapshots of the track of drifter no. 35660 for SeptemberOctober 2003 (see Fig. S6 in the Supplement). Being at the beginning of September in the main stream (Fig. 7a), it has drifted round the cyclone for the first half of September, then round the anticyclone for the second half of September and at the beginning of October. Eventually drifter no. 35660 crossed the latitude $42^{\circ} \mathrm{N}$ (Fig. 7b) and moved to the north lugged by modified subtropical waters.

\subsection{The effect of possible altimetry errors on statistical features of Lagrangian transport}

It has been shown statistically that the average northward component of the AVISO velocity field dictates preferred near-surface transport pathways of subtropical waters in the central JS. The ability of satellite altimetry to accurately measure sea level anomalies has vastly improved over the last decade. However, there are still some measurement errors due to different reasons that lead to errors in the velocity field provided by AVISO.

In this section we discuss the possible effect of errors in the altimetry field on our simulation results. The AVISO velocity field has errors as compared with a "true" velocity field. The difference could be simulated by adding a noise $\Delta(u, v)$ in the velocity data. The question is how reliable are our statistical simulation results based on an imperfect AVISO velocity field? All the simulation results, based on the average AVISO velocity as in Fig. 1, are supposed to be reliable because 
the errors are averaged out for 22 years. As to other simulation results, they depend on possible noise $\Delta v$ in the AVISO northward component $v_{+}$which could, in principle, change the results but only if the noise were strong enough to change the direction of the meridional velocity, i.e. if $\Delta v>|v|$. If the average AVISO northward component $\left\langle v_{+}\right\rangle$is large enough as in the areas with dominated northward currents, we do not expect that it would be changed there significantly under the influence of noise. So, locations of the preferred transport pathways are not expected to be changed significantly.

If the average AVISO northward component $\left\langle v_{+}\right\rangle$is small, then two options are possible.

1. It is small due to domination of a southward current somewhere, i.e. $v_{-} \gg \Delta v$. It is clear that possible noise has practically no effect on northward transport in this case. For example, the forbidden zone in Fig. 2a to the south off Vladivostok, where northward transport has not been observed during the whole observation period, should be located there at any realistic level of noise because it exists due to the domination of a sufficiently strong southward jet (VMJ in Fig. 1).

2. The average AVISO northward component $\left\langle v_{+}\right\rangle$is small due to a smallness of the absolute velocity, i.e. $\sqrt{u^{2}+v^{2}} \sim \Delta v$. In this case northward and southward transports are equalised, and they are small if the noise is small enough. Such a situation is unlikely along the Subpolar Front because of the presence of numerous mesoscale eddies along the front where the absolute velocities are not small.

The influence of possible errors in altimetry-derived velocity field on concrete mesoscale features has been studied by Harrison and Glatzmaier (2012), Hernández-Carrasco et al. (2011) and Keating et al. (2011) by analysing how an additional noise in the advection equations might change Lagrangian coherent structures revealed by the finite-time and finite-size Lyapunov techniques. Strongly attracting and repelling individual Lagrangian coherent structures in the California Current System have been shown to be robust to perturbations of the velocity field of over $20 \%$ of the maximal regional velocity (Harrison and Glatzmaier, 2012). Individual trajectories have been shown to be sensitive to small and moderate noisy variations in the velocity field but statistical characteristics and large-scale structures like mesoscale eddies and jets are not (Cotte et al., 2010; Hernández-Carrasco et al., 2011; Keating et al., 2011).

\section{Conclusions}

The main results of altimetry-based simulation and analysis of the northward near-surface Lagrangian transport of subtropical water across the Japan Sea frontal zone for the period from 2 January 1993 to 15 June 2015 are the following.
1. A methodology to simulate and analyse Lagrangian large-scale transport in frontal areas is developed (tasks 1-4 in Sect. 2).

2. There are "forbidden" zones in the Japan Sea where the northward transport has not been found during all the observation period (the rectangles in Fig. 2a). The "forbidden" zone to the south of Vladivostok exists due to a quasi-permanent southward jet there (VMJ in Fig. 1). The other "forbidden" zone exists due to the presence of a quasi-permanent topographically constrained anticyclonic eddy with centre at about $41.3^{\circ} \mathrm{N}, 134^{\circ} \mathrm{E}$ in the deep Japan Basin and the eastward zonal jet blocking northward transport there (AC in Fig. 1).

3. Northward near-surface Lagrangian transport of subtropical water across the Subpolar Front has been statistically shown to be meridionally inhomogeneous with specific gates and barriers in the frontal zone whose locations are determined by the local advection velocity field (the pronounced peaks in Figs. 3 and 4).

4. The transport through the gates has been shown to occur by a portion-like manner, i.e. those gates "open" during specific time intervals (a patchiness in Fig. 5 and Figs. S2 and S3 in the Supplement).

5. The gates "open" due to suitable dispositions of mesoscale frontal eddies facilitating propagation of subtropical waters to the north. It is documented for the western, central and eastern gates with the help of different kinds of Lagrangian maps and validated by some tracks of available drifters (the intrusions of subtropical tracers around the eddies in Figs. 6, 7, and Figs. S5 and S6 in the Supplement). In particular, invasion of tropical and subtropical marine organisms in the northern part of the sea, to the southern coast of Russia, can be explained by the presence of vortex streets at the western gate (Fig. 6).

\section{Data availability}

The altimeter products were produced by Ssalto/Duacs and distributed by Aviso, with support from Cnes (http://www. aviso.altimetry.fr/duacs/).

The drifter data were collected and made freely available by the Global Drifter Program (http://www.aoml.noaa.gov/ phod/dac) of the National Oceanic and Atmospheric Administration, NOAA, USA. The data used cover the period up to September 2016.

For any questions regarding the simulations data, we encourage the reader to contact the author at uleysky@poi.dvo.ru. They are very large files of a few gigabytes in size that cannot be deposited in a reliable public data repository. 
Competing interests. The authors declare that they have no conflict of interest.

\section{The Supplement related to this article is available online at doi:10.5194/npg-24-89-2017-supplement.}

Acknowledgements. This work was supported by the Russian Science Foundation (project no. 16-17-10025). A publication cost is covered, in part, by the Office of Naval Research grant no. N00014-16-1-2492. The altimeter products were distributed by AVISO with support from CNES.

Edited by: A. Turiel

Reviewed by: three anonymous referees

\section{References}

Budyansky, M. V., Goryachev, V. A., Kaplunenko, D. D., Lobanov, V. B., Prants, S. V., Sergeev, A. F., Shlyk, N. V., and Uleysky, M. Y.: Role of mesoscale eddies in transport of Fukushimaderived cesium isotopes in the ocean, Deep Sea Res. Part I, 96, 15-27, doi:10.1016/j.dsr.2014.09.007, 2015.

Chang, K.-I., Teague, W., Lyu, S., Perkins, H., Lee, D.-K., Watts, D., Kim, Y.-B., Mitchell, D., Lee, C., and Kim, K.: Circulation and currents in the southwestern East/Japan Sea: Overview and review, Prog. Oceanogr., 61, 105-156, doi:10.1016/j.pocean.2004.06.005, 2004.

Choi, B.-J., Haidvogel, D. B., and Cho, Y.-K.: Nonseasonal sea level variations in the Japan/East Sea from satellite altimeter data, J. Geophys. Res.-Ocean., 109, C12028, doi:10.1029/2004jc002387, 2004.

Cotte, C., d'Ovidio, F., Chaigneau, A., Levy, M., TaupierLetage, I., Mate, B., and Guinet, C.: Scale-dependent interactions of Mediterranean whales with marine dynamics, Limnol. Oceanogr., 56, 219-232, doi:10.4319/lo.2011.56.1.0219, 2010.

Danchenkov, M., Lobanov, V., Riser, S., Kim, K., Takematsu, M., and Yoon, J.-H.: A History of Physical Oceanographic Research in the Japan/East Sea, Oceanography, 19, 18-31, doi:10.5670/oceanog.2006.41, 2006.

Harrison, C. S. and Glatzmaier, G. A.: Lagrangian coherent structures in the California Current System - sensitivities and limitations, Geophys. Astrophys. Fluid Dynam., 106, 22-44, doi:10.1080/03091929.2010.532793, 2012.

Hernández-Carrasco, I., López, C., Hernández-García, E., and Turiel, A.: How reliable are finite-size Lyapunov exponents for the assessment of ocean dynamics?, Ocean Model., 36, 208-218, doi:10.1016/j.ocemod.2010.12.006, 2011.

Hernández-Carrasco, I., López, C., Orfila, A., and HernándezGarcía, E.: Lagrangian transport in a microtidal coastal area: the Bay of Palma, island of Mallorca, Spain, Nonlin. Processes Geophys., 20, 921-933, doi:10.5194/npg-20-921-2013, 2013.

Isoda, Y.: Warm eddy movements in the eastern Japan Sea, J. Oceanogr., 50, 1-15, doi:10.1007/bf02233852, 1994.
Ito, M., Morimoto, A., Watanabe, T., Katoh, O., and Takikawa, T.: Tsushima Warm Current paths in the southwestern part of the Japan Sea, Prog. Oceanogr., 121, 83-93, doi:10.1016/j.pocean.2013.10.007, 2014.

Ivankova, V. N. and Samuilov, A. E.: New fish species for the USSR waters and an invasion of heat-loving fauna in the north-western part of the Japan Sea, Voprosy Ihtiologii, 19, 449-550, 1979.

Keating, S. R., Smith, K. S., and Kramer, P. R.: Diagnosing Lateral Mixing in the Upper Ocean with Virtual Tracers: Spatial and Temporal Resolution Dependence, J. Phys. Oceanogr., 41, 1512 1534, doi:10.1175/2011JPO4580.1, 2011.

Kim, T. and Yoon, J.-H.: Seasonal variation of upper layer circulation in the northern part of the East/Japan Sea, Cont. Shelf Res., 30, 1283-1301, doi:10.1016/j.csr.2010.04.006, 2010.

Lee, D.-K. and Niiler, P.: Eddies in the southwestern East/Japan Sea, Deep Sea Res. Part I, 57, 1233-1242, doi:10.1016/j.dsr.2010.06.002, 2010.

Lee, D.-K. and Niiler, P. P.: The energetic surface circulation patterns of the Japan/East Sea, Deep Sea Research Part II, 52, 1547 1563, doi:10.1016/j.dsr2.2003.08.008, 2005.

Lipphardt, B. L., Small, D., Kirwan, A. D., Wiggins, S., Ide, K., Grosch, C. E., and Paduan, J. D.: Synoptic Lagrangian maps: Application to surface transport in Monterey Bay, J. Marine Res., 64, 221-247, doi:10.1357/002224006777606461, 2006.

Mitchell, D. A., Teague, W. J., Wimbush, M., Watts, D. R., and Sutyrin, G. G.: The Dok Cold Eddy, J. Phys. Oceanogr., 35, 273288, doi:10.1175/jpo-2684.1, 2005.

Nikitin, A. A., Lobanov, V. B., and Danchenkov, M. A.: Possible pathways for transport of warm subtropical waters to the area of the Far Eastern Marine Reserve, Izvestiya TINRO, 131, 41-53, 2002.

Park, K.-A., Chung, J. Y., and Kim, K.: Sea surface temperature fronts in the East (Japan) Sea and temporal variations, Geophys. Res. Lett., 31, L07304, doi:10.1029/2004gl019424, 2004.

Prants, S., Ponomarev, V., Budyansky, M., Uleysky, M., and Fayman, P.: Lagrangian analysis of the vertical structure of eddies simulated in the Japan Basin of the Japan/East Sea, Ocean Model., 86, 128-140, doi:10.1016/j.ocemod.2014.12.010, 2015.

Prants, S. V.: Dynamical systems theory methods to study mixing and transport in the ocean, Phys. Scripta, 87, 038115, doi:10.1088/0031-8949/87/03/038115, 2013.

Prants, S. V.: Chaotic Lagrangian transport and mixing in the ocean, Eur. Phys. J. Spec. Top., 223, 2723-2743, doi:10.1140/epjst/e2014-02288-5, 2014.

Prants, S. V.: Backward-in-time methods to simulate large-scale transport and mixing in the ocean, Phys. Scripta, 90, 074054, doi:10.1088/0031-8949/90/7/074054, 2015.

Prants, S. V., Budyansky, M. V., Ponomarev, V. I., and Uleysky, M. Y.: Lagrangian study of transport and mixing in a mesoscale eddy street, Ocean Model., 38, 114-125, doi:10.1016/j.ocemod.2011.02.008, 2011a.

Prants, S. V., Uleysky, M. Y., and Budyansky, M. V.: Numerical simulation of propagation of radioactive pollution in the ocean from the Fukushima Dai-ichi nuclear power plant, Dokl. Earth Sci., 439, 1179-1182, doi:10.1134/S1028334X11080277, $2011 \mathrm{~b}$.

Prants, S. V., Ponomarev, V. I., Budyansky, M. V., Uleysky, M. Y., and Fayman, P. A.: Lagrangian analysis of mixing and transport of water masses in the marine bays, Izvestiya, Atmos. Ocean. Phys., 49, 82-96, doi:10.1134/S0001433813010088, 2013. 
Prants, S. V., Budyansky, M. V., and Uleysky, M. Y.: Lagrangian study of surface transport in the Kuroshio Extension area based on simulation of propagation of Fukushimaderived radionuclides, Nonlin. Processes Geophys., 21, 279-289, doi:10.5194/npg-21-279-2014, 2014a.

Prants, S. V., Budyansky, M. V., and Uleysky, M. Y.: Lagrangian fronts in the ocean, Izvestiya, Atmos. Ocean. Phys., 50, 284-291, doi:10.1134/s0001433814030116, 2014b.

Prants, S. V., Budyansky, M. V., and Uleysky, M. Y.: Identifying Lagrangian fronts with favourable fishery conditions, Deep Sea Res. Part I, 90, 27-35, doi:10.1016/j.dsr.2014.04.012, 2014c.

Shin, C.-W.: Characteristics of a Warm Eddy Observed in the Ulleung Basin in July 2005, Ocean Polar Res., 31, 283-296, doi:10.4217/opr.2009.31.4.283, 2009.

Takematsu, M., Ostrovski, A. G., and Nagano, Z.: Observations of Eddies in the Japan Basin Interior, J. Oceanogr., 55, 237-246, doi:10.1023/a:1007846114165, 1999.
Talley, L., Min, D.-H., Lobanov, V., Luchin, V., Ponomarev, V., Salyuk, A., Shcherbina, A., Tishchenko, P., and Zhabin, I.: Japan/East Sea Water Masses and Their Relation to the Sea's Circulation, Oceanography, 19, 32-49, doi:10.5670/oceanog.2006.42, 2006.

Uleysky, M. Y., Budyansky, M. V., and Prants, S. V.: Effect of dynamical traps on chaotic transport in a meandering jet flow, Chaos, 17, 043105, doi:10.1063/1.2783258, 2007.

Yoon, J.-H. and Kim, Y.-J.: Review on the seasonal variation of the surface circulation in the Japan/East Sea, J. Marine Syst., 78, 226-236, doi:10.1016/j.jmarsys.2009.03.003, 2009. 